\title{
Retraction Note to: Prognostic factors for the outcome of arthroscopic capsular repair of peripheral triangular fibrocartilage complex tears
}

\author{
Young Hak Roh ${ }^{1} \cdot$ Yeo-Hon Yun ${ }^{2}$. Dong Jun $\mathrm{Kim}^{2} \cdot$ Muhyun Nam ${ }^{2} \cdot$ Hyun Sik Gong ${ }^{3} \cdot$ Goo Hyun Baek
}

Published online: 2 February 2022

c) Springer-Verlag GmbH Germany, part of Springer Nature 2022

\section{Retraction to: Archives of Orthopaedic and Trauma Surgery (2018) 138:1741-1746 https://doi.org/10.1007/s00402-018-2995-9}

The Editor-in-Chief has retracted this article because an investigation by the Institutional Review Board, Gil Medical Center, College of Medicine, Gachon University, has concluded that the study reported by the authors did not match the research proposal submitted to the Institutional Review Board for approval. Young Hak Roh stated on behalf of all co-authors that they do not agree with this retraction.

Publisher's Note Springer Nature remains neutral with regard to jurisdictional claims in published maps and institutional affiliations.

The original article can be found online at https://doi.org/10.1007/ s00402-018-2995-9.

Young Hak Roh

ryhak@hanmail.net

1 Department of Orthopaedic Surgery, Ewha Womans University Medical Center, Ewha Womans University College of Medicine, 1071 Anyangcheon-ro, Yangcheon-gu, Seoul 07985, South Korea

2 Department of Orthopaedic Surgery, Ewha Womans University Medical Center, Ewha Womans University College of Medicine, Seoul, South Korea

3 Department of Orthopaedic Surgery, Seoul National University College of Medicine, Seoul, South Korea 